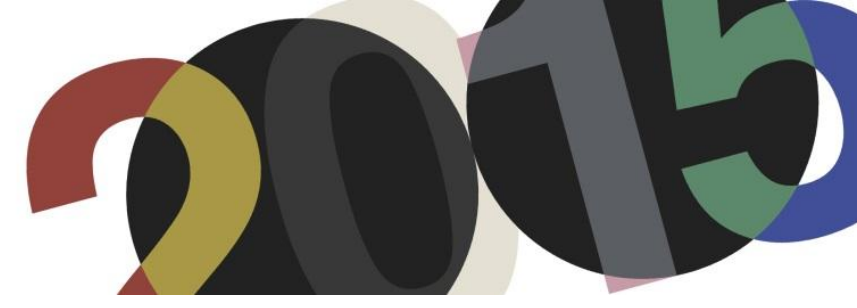

DOI: http://dx.doi.org/10.4995/LC2015.2015.648

\title{
Maestro y discípulos: \\ Japón y el pabellón para la Exposición Internacional de París de 1937
}

\author{
P.J. Gutiérrez Calderón \\ Escuela Técnica Superior de Arquitectura de Madrid - Kyoto Seika University
}

\begin{abstract}
Resumen: En 1937, Japón presentaba para la Exposición Internacional de París un pabellón que rompía con los modelos de arquitectura tradicional y vernácula que había construido en anteriores exposiciones. El descaro de la propuesta generó no poca controversia en el país nipón debido al lenguaje empleado, alejado de las tipologías y sistemas constructivos autóctonos para introducir un nuevo modelo, aplicando nuevos materiales como acero y vidrio. Entre el primer proyecto presentado a concurso, obra de Kunio Mayekawa y el proyecto finalmente construido, obra de Junzo Sakakura, aparecerá un común denominador en la figura del maestro: Le Corbusier. El artículo analiza la influencia que supuso el maestro en la realización de los proyectos. Mientras Mayekawa evolucionaba buscando su propio camino, Sakakura diseñará el pabellón en el estudio de la calle de Sèvres, influenciado por las enseñanzas y sugerencias de Le Corbusier, para conseguir aunar en su arquitectura la profunda tradición japonesa con la modernidad. El pabellón puede considerarse pionero de la arquitectura moderna japonesa que entra a formar parte de la escena internacional, alzándose con uno de los premios de arquitectura otorgados por la organización francesa, junto a los pabellones de Aalto y J. L. Sert.
\end{abstract}

Abstract: In 1937, a Japanese Pavilion was presented to the International Exhibition in Paris. This pavilion broke with the traditional and vernacular architecture that Japan had built in previous exhibitions. The audacity of the proposal generated a lot of controversy in the japanese country, due to its language, away from the native typologies and constructive systems. Indeed, the approach introduced a new model, using new materials such as steel and glass. The first project submitted to the competition, designed by Kunio Mayekawa, and the final built project, designed by Junzo Sakakura, have a common denominator represented by the figure of the Master: Le Corbusier. The article analyzes the influence of the Master in the ejecution of the projects. While Mayekawa progressed looking for its own way, Sakakura designed the pavilion in Sèvres Street Studio, influenced by the training and suggestions of Le Corbusier. Then, he managed to combine in its architecture deep Japanese tradition with modernity. The pavilion can be considered as a pioneering work of modern Japanese architecture that becomes part of the international scene, indeed, it was awarded with one of the architectural prizes granted by the French organization, together with the pavillions designed by Aalto and J.L.Sert.

Palabras clave: Mayekawa; Sakakura; Le Corbusier; Pabellón japonés; Arquitectura moderna. Keywords: Mayekawa; Sakakura; Le Corbusier; Japanese Pavilion; Modern Architecture. 


\section{Introducción, antecedentes y objetivos.}

En 1937, Japón presentaba para la Exposición Internacional de París un pabellón que rompía con los modelos de arquitectura tradicional y vernácula que había construido en anteriores exposiciones. El descaro de la propuesta generó no poca controversia en el país nipón debido al lenguaje empleado, alejado de las tipologías y sistemas constructivos autóctonos para introducir un nuevo modelo, aplicando nuevas tecnologías como acero y vidrio.

Para entender la disgresión estilística que supone este pabellón y la evolución que supuso para la arquitectura japonesa en los inicios del siglo XX hay que volver la mirada a dos arquitectos protagonistas del proyecto, que introducían de manera decidida el lenguaje moderno en un país cuyo peso de la tradición hacía muy difícil conseguir esa evolución. El primero, Kunio Maekawa, ganaba el concurso convocado al efecto pero que no llegará a construirse por ser considerado demasiado avanzado y poco japonés. El segundo, Junzo Sakakura, rediseñará y materializará el proyecto con un lenguaje moderno, gracias -en parte- a la intervención del gobierno francés. Ambos, unos años antes, habían sido colaboradores en la rue de Sèvres, París. Ambos vivirán la arquitectura como protagonistas en la introducción del movimiento moderno en Japón, poniendo en práctica las enseñanzas que recibieron de su maestro Le Corbusier.

El objetivo que plantea este artículo "Maestro y discípulos: Japón y el pabellón para la Exposición Internacional de París de 1937" es analizar el pabellón que representó a Japón en la exposición "Artes y Técnicas de la Vida Moderna", estableciendo analogías con la obra del maestro Le Corbusier para discernir los puntos de contacto e influencias que hicieron emerger la arquitectura moderna en Japón, a partir del estudio del proyecto ganador del concurso, obra de Maekawa, y el proyecto finalmente ejecutado en la colina de Trocadero, obra de Sakakura, frente a la Torre Eiffel.

\section{Japón en la Exposición de París: un pabellón en tiempos convulsos.}

"Una gran época ha comenzado. Existe un espiritu nuevo. Existe una multitud de obras concebidas en este espíritu nuevo que se encuentran, particularmente, en la producción industrial. La arquitectura se ahoga con las costumbres. Los "estilos" son una mentira. El estilo es una unidad de principio que anima todas las obras de una época, el resultado de un estado de ánimo que tiene su propio carácter especial. Nuestra propia época determina, día a día, su propio estilo. Nuestro ojos, desgraciadamente, no son capaces de discernirlo".

\section{Le Corbusier ${ }^{l}$}

Durante la década de los años treinta, Europa se enfrentaba a un período de gran agitación, marcado por la inestabilidad social, política y económica. Las secuelas de la Primera Guerra Mundial habían derivado en una grave crisis económica, y un auge preocupante del nacionalismo, exacerbado en Alemania y Rusia que mostraban su autoritarismo político mermando la ferviente actividad artística de los años veinte, persiguiendo y cerrando escuelas de diseño innovadoras o transgresoras como el caso de la Bauhaus. Es en este contexto internacional cuando se decidió convocar en París en 1934 una Exposición Internacional programada para 1937 bajo el título de "Arte y Tecnología en la Vida Moderna" cuyos objetivos eran por un lado mostrar los nuevos avances de la tecnología y su convivencia con el mundo del arte, como dos realidades no distantes sino complementarias y necesarias, unidas por la nueva vida moderna, y por otro intentar -en el contexto de la grave crisis económica y la inestabilidad política que precedería a la segunda Guerra Mundial- promover la paz con el acercamiento de los distintos países. A pesar de que en 1936 - un año antes de su inicio- la situación se agravaría

\footnotetext{
${ }^{1}$ Le Corbusier: Hacia una arquitectura. Barcelona: Ediciones Apóstrofe, S.L. 1998. pp. 68-69.
} 
con la ocupación alemana de la zona de Renania y con el estallido de la Guerra Civil española, Leon Blum, jefe del gabinete del Frente Popular francés dio un nuevo impulso para su definitiva ejecución e inauguración en mayo de 1937, invitando a cuarenta países entre los que se encontraba Japón, que aceptó la invitación.

En 1936, el país nipón creó una comisión técnica para el desarrollo del futuro pabellón, que pretendía enseñar al mundo la imagen de un país civilizado, moderno, ensalzando sus tradiciones y difundiendo la sutileza de la cultura japonesa, mostrándose como un país atractivo para el turismo, a la vez que procuraba evitar cualquier gesto de tipo político o belicista, a pesar de haber comenzado las hostilidades contra China, que acabarán con la invasión en 1937, o de haber firmado el "Pacto Antikomitern" con la Alemania nacionalsocialista debido a la amenaza comunista rusa. Con la idea de mostrar de manera aséptica la cultura y la tecnología, y con el espíritu de desarrollar futuras relaciones comerciales, la comisión para la Exhibición de París fue formada por el Ministerio de Comercio, la Cámara de Comercio, la Asociación del Comercio de Japón y la Asociación para la Promoción Internacional de la Cultura. Fue ésta última la que se encargaría de la gestión del diseño del pabellón, delegando su comisariado a Hideto Kishida, profesor de la Tokyo University, que convocaría un concurso de arquitectura restringido para definir el pabellón que representaría a Japón en la Exposición Internacional de París. Maeda, Mayekawa, Ichiura, Yoshida y Taniguchi fueron los arquitectos invitados que presentarían sus propuestas, defendiendo una arquitectura para los nuevos tiempos, ante un clima conservador y ultranacionalista, muy apegado a la arquitectura tradicional y enfrentado a la novedosa arquitectura moderna ${ }^{2}$.

\subsection{El proyecto ganador del concurso: Kunio Mayekawa.}

Los pabellones presentados a anteriores exposiciones internacionales habían sido extremadamente tradicionales tanto en la tipología como en el sistema constructivo empleado. La imagen de la casa tradicional japonesa, de un templo budista o un santuario sintoísta eran temas recurrentes para asociar la arquitectura del país nipón a los pabellones expositivos, como el "Ho-o-den" - reinterpretación del Pabellón del Fénix en Uji- presentado a la "World's Columbian Exposition" de Chicago de 1893.

Era de esperar que los pabellones se asemejaran al modelo historicista que Japón había presentado en ocasiones anteriores, buscando una imagen reconocible que la asociara a los templos a partir del trabajo con la madera usada para la estructura y cerramiento - y la ejecución de la cubierta al modo tradicional, que establecía una mímesis con el lenguaje de la arquitectura vernácula japonesa. Sin embargo, la propuesta ganadora del concurso, la de Mayekawa, establecía una ruptura con el modelo tradicional para introducir en su arquitectura los nuevos paradigmas que había aprendido de su maestro Le Corbusier con el que había estado trabajando durante los años 1928 a 1930.

Mayekawa, atendiendo a los requerimientos del país organizador y al título de la exposición, diseñó un pabellón construido en acero y vidrio, con un lenguaje propio alejado de la imagen tradicional japonesa. Partiendo del lugar y la topografía de la zona habilitada para su construcción, con unas vistas excepcionales hacia el Sena y la Torre Eiffel, Kunio Mayekawa quería explorar la configuración de los diferentes niveles del pabellón para adecuarse a la pendiente y ofrecer una solución arquitectónica apropiada al lugar. Para ello, había escrito a su maestro Le Corbusier ${ }^{3}$ con la intención de que le informase desde París de las características de la parcela asignada a Japón, solicitándole que le enviara alguna fotografía de la colina de Trocadero.

\footnotetext{
${ }^{2}$ Noboru, Kawazoe: Contemporary Japanese Architecture. Tokyo: Kokusai Bunka Shinkokai, 1968.

${ }^{3}$ Correspondencia entre Mayekawa y Le Corbusier. Fundación Le Corbusier. París. Cartas E2-15, 174-182.
} 
Con esta información, Mayekawa presentó al concurso una propuesta que se adaptaba a los nuevos tiempos, influenciado por las lecturas de "Vers une architecture" y "L'art décoratif d'aujourd' hui" "libro que traducirá a su lengua materna tras regresar a Japón, después de completar su formación en el estudio de la calle Sèvres-.

El proyecto presentado, que evolucionaba un modelo estudiado en su trabajo de graduación, se adaptaba a la topografía, fragmentándose en dos volúmenes paralelepipédicos, perpendiculares entre sí que finalizaban en un tercer volumen curvo a modo de mirador sobre la colina.

El acceso se desarrollaba en la cota superior, con una fachada lineal, retranqueada tras una marquesina modulada por pilotis y un cuerpo vertical a modo de torre donde se disponía la entrada, coronando el alzado con grandes letras que anunciaban el país.

El modelo, determinado por los materiales a emplear de acero y vidrio -y por tanto limitado a un sistema constructivo sencillo de montar-, presentaba un programa determinado por el acceso, la posición en la ladera, y las relaciones que surgían entre las diferentes cotas del terreno y los jardines diseñados al efecto.

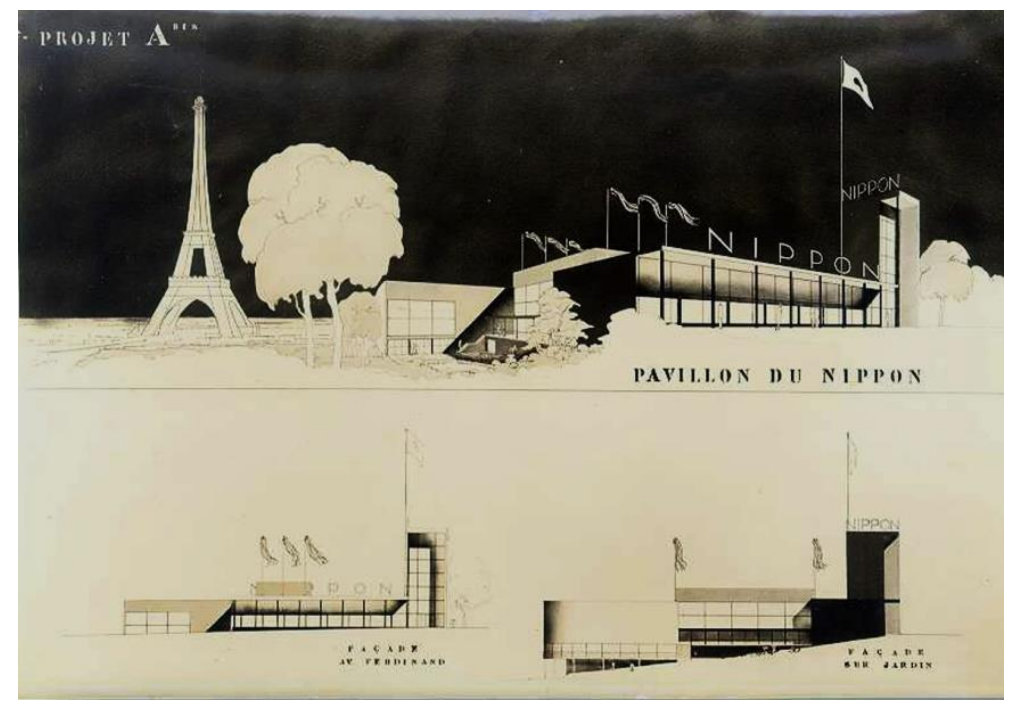

1. Pavillon du Nippon. 1937. Fotografía de la propuesta presentada a concurso enviada por Mayekawa a Le Corbusier.

De este modo, entrando a través del pórtico, Mayekawa disponía un espacio diáfano, abierto totalmente a la fachada mediante grandes planos de vidrio, acotando dos espacios para un tocador y un salón, y una gran zona destinada a la sección comercial. A una cota más deprimida, pero dentro de un volumen de mayor altura que el anterior, se disponía la sección científica que ocupaba todo el espacio con una proporción significativamente diferenciada. Éste se abría al exterior mediante una marquesina sobre pilotis, que permitía un porche sobre el jardín en la cara noreste, y que mediante un recorrido exterior, bajando unas escaleras, llegaba al plano de suelo donde se disponía la terraza restaurante. En este nivel, se establecía la continuidad del jardín con la zona de descanso, estudiando muy bien la relación entre exterior e interior, que servía además de antesala para el gran espacio representativo del proyecto. En este punto el terreno natural continuaba deprimiéndose en el exterior, y tomaba protagonismo la última pieza diseñada en curva que se alzaba sobre el terreno mediante pilotis exentos.

\footnotetext{
${ }^{4}$ Hiroshi, Yamaguchi: "Kunio Mayekawa and Japanese Modern Architecture". The Exhibition Organizing Committee for Kunio Maekawa Retrospective (ed): The Work of Kunio Maekawa: A Pioneer of Japanese Modern Architecture. Tokyo: Bijutsu Shuppan-Sha, 2006. pp 201-203
} 


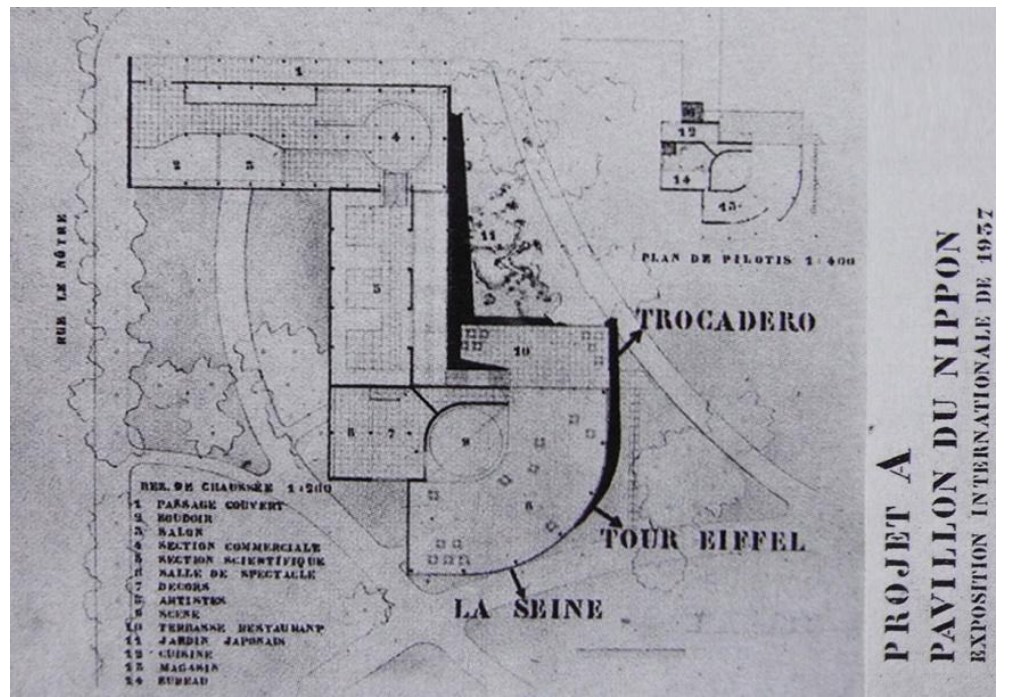

2. Japanese Pavilion, 1937. Paris International Exposition. Planta de la propuesta para el pabellón de Japón presentada al concurso. Kunio Mayekawa. Montaje del autor.

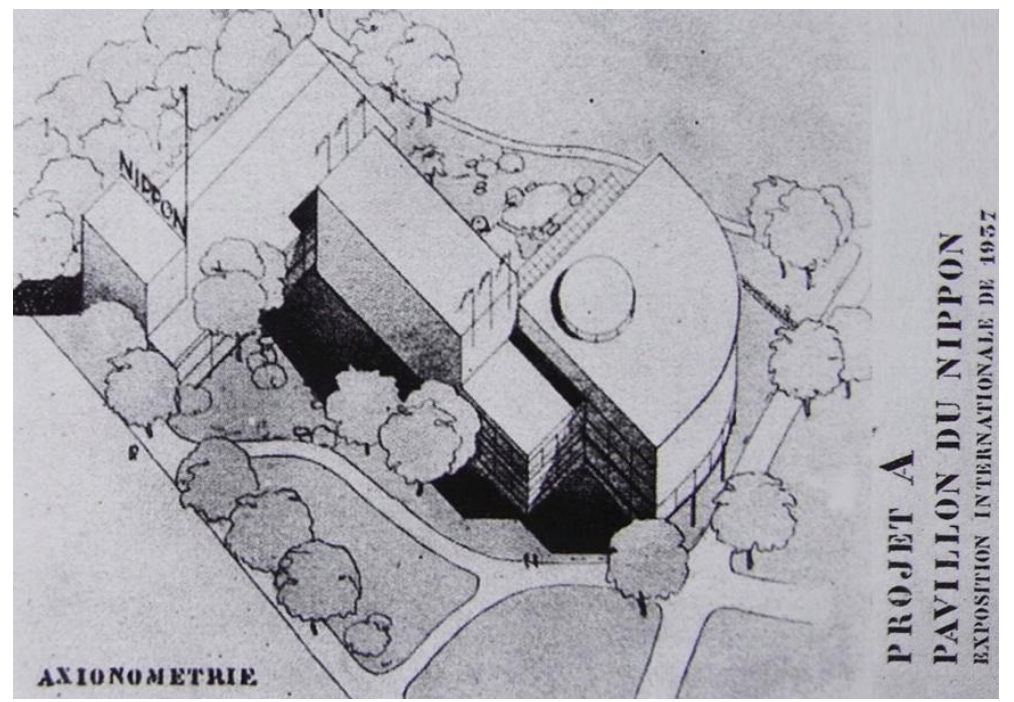

3. Japanese Pavilion, 1937. Paris International Exposition. Axonometría de la propuesta para el pabellón de Japón presentada al concurso. Kunio Mayekawa. Montaje del autor.

La sala de espectáculo era la protagonista del proyecto, el epicentro desde donde se divisaba, debido a su posición privilegiada en alto, la colina de Trocadero, la Torre Eiffel y el río Sena. Aprovechando esa posición introducía la forma curva para divisar todo el entorno, sin discontinuidad, con una doble altura donde comparar frente a la vista parisina, las vistas de Japón montadas a lo largo de este "panorama”. Así el visitante contrastaba la visión que le brindaba el lugar parisino frente a la visión de Japón ofrecida por la arquitectura de Mayekawa, que con vistas a atraer el turismo, mostraba unos paneles con fotomontajes del Gran Buda de Kamakura, el torii del santuario sintoísta de Itsuikushima en Mijayima, el castillo de Himeji, los cerezos en flor, y el monte Fuji. 


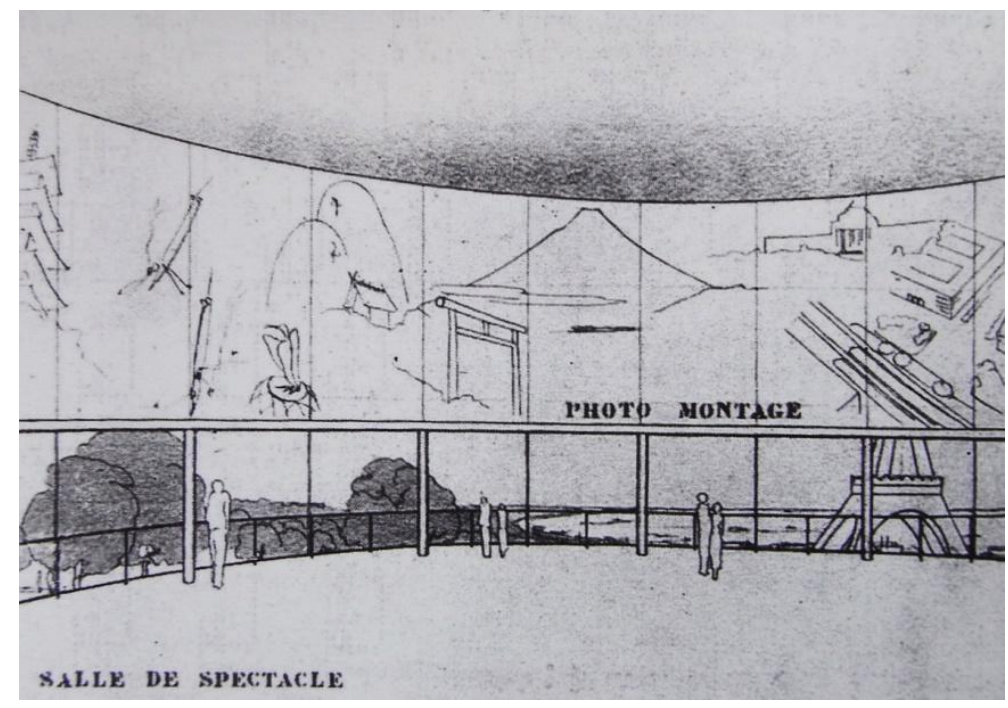

4. Japanese Pavilion, 1937. Paris International Exposition. Vista interior de la sala de espectáculos de la propuesta para el pabellón de Japón presentada al concurso. Kunio Mayekawa.

El gobierno japonés quería mostrarse al mundo como una nación democrática, industrial y económicamente avanzada, con un rico patrimonio cultural y natural. Sin embargo, a nivel interno no parecía que las decisiones fueran muy democráticas, tal y como se desarrolló el encargo del pabellón. El peso de la tradición era tan marcado, que el Comité para la Exposición de París aplazó la decisión de construir el proyecto ganador porque el diseño "no era típico japonés", manifestando que debería capturar el espíritu de la arquitectura japonesa, construyéndose con técnicas y materiales locales a pesar de ir en contra de las condiciones de participación de la exposición impuestas por Francia -que requerían el uso de materiales modernos-, incluso amenazando con abandonar la exposición si no se le permitía trabajar con los materiales y técnicas constructivas tradicionales.

Kishida, el comisario encargado de la selección, concluyó que la propuesta de Mayekawa confrontaba las dos corrientes arquitectónicas que habían surgido en Japón con los arquitectos modernos, -unos inspirados en el estilo occidental, frente a aquellos que estaban convencidos de que no sería posible adoptar ese nuevo lenguaje arquitectónico, manteniéndose en una corriente historicista ${ }^{6}$ - En esta tesitura se planteaba el dilema de "qué era lo típico japonés", marchándose a Berlín para inspeccionar las instalaciones olímpicas de 1936 sin esperar a tomar una decisión final. El Comité para la Exposición de París eligió el diseño de Kenjiro Maeda por ser un diseño más tradicional. Sin embargo, para complicar más la decisión, el gobierno francés requería en sus bases que todos los edificios de la exposición fueran construidos con materiales modernos -acero y vidrio- y ejecutados por trabajadores franceses. Estos requerimientos obligaron a los representantes japoneses a replantearse nuevamente el fallo, teniendo en cuenta que el diseñador debería estar familiarizado con las técnicas y condiciones laborales francesas, hablar el idioma y estar preparado para supervisar el trabajo desde París. Desechando a los arquitectos que habían sido elegidos por Kishida, seleccionaron a un joven arquitecto que acababa de regresar de París tras una estancia de siete años trabajando en el estudio de Le Corbusier: Junzo Sakakura.

\footnotetext{
5 Tadayoshi, Fujiki: “Tokyo-Paris 1936-1937”. En Process: Architecture. "Sakakura Associates” May 1993, n¹10. Tokyo: Process Architecture CO. Ldt. 1993. pp.33-38.

${ }^{6}$ Reynolds, Jonathan M.: Maekawa Kunio and the Emergence of Japanese Modernist Architecture. Berkeley: University of California Press, 2001. pp. 36-37.
} 


\subsection{El proyecto realizado: Junzo Sakakura.}

Tras su retorno a Japón en la primavera de 1936, Junzo Sakakura volvía a París en septiembre de ese mismo año con un encargo envenenado: ser capaz de responder a las expectativas creadas por el Comité para la Exposición de París de crear un pabellón con un marcado estilo japonés pero adaptado a las demandas de modernidad exigidas por la organización francesa. A su llegada a París, y habiendo realizado un estudio pormenorizado del emplazamiento del pabellón, Junzo Sakakura comenzó a desarrollar el nuevo proyecto en una esquina de la oficina de Le Corbusier en la rue Sèvre. Tras siete años trabajando allí, contó con la ayuda de un antiguo discípulo de Le Corbusier que en esos momentos trabaja por su cuenta -Pollack-, un miembro del estudio de Le Corbusier -Bosch-, y el estudiante Seichi Inoue.

Con un profundo respeto por la naturaleza donde se asentaba, el proyecto de Sakakura se adaptaba tanto a la topografía existente como a la vegetación y árboles de la parcela atendiendo a un estudio detallado del espacio, las alturas y la relación interior-exterior con el paisaje en el que se insertaba. El diseño partía de un volumen principal, que se fragmentaba en distintas alturas, y al que se anexionaban dos cuerpos: uno situado en la cota más alta de la parcela, al oeste, y otro cuerpo formado por una rampa adosada al este, que separándose del volumen principal, se constituía como un elemento autónomo, abrazando la vegetación, para conectar la cota superior del edificio principal, la cota inferior, y prolongar el recorrido marcando la salida en el punto más deprimido del terreno.

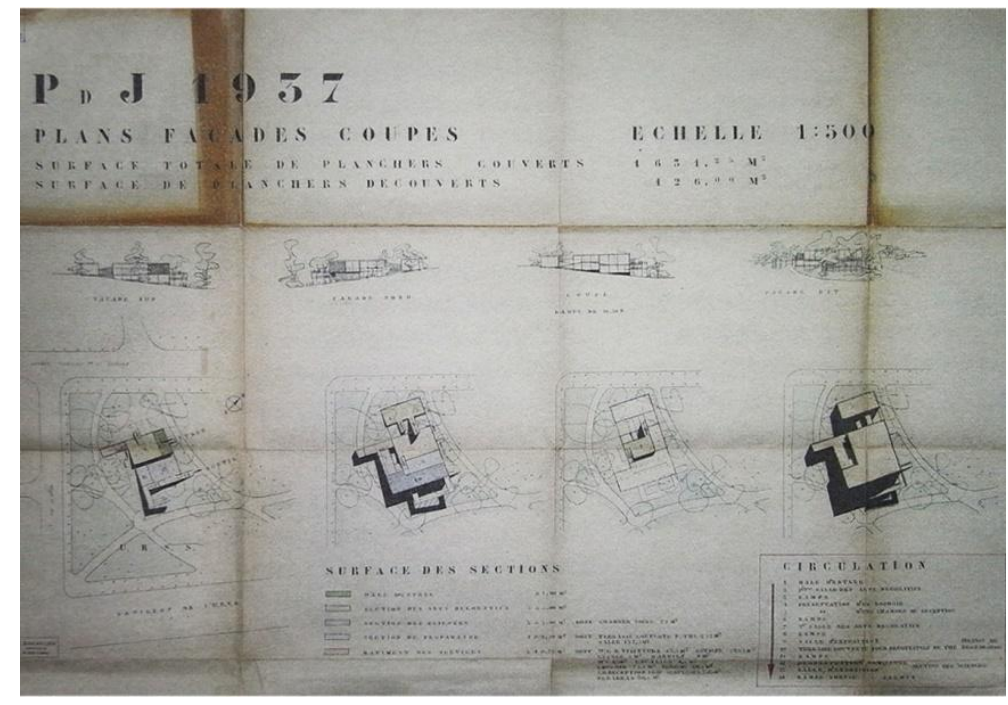

5. Pavillon du Japon, 1937. Exposition Internationale des Arts et des Techniques Appliques a la Vie Moderne. Paris. Plano Original de plantas y alzados a escala 1:500.

El proyecto entendía perfectamente la topografía y se desarrollaba insertándose en ella. La entrada se realizaba por la zona central, a una cota intermedia, a través de un pórtico que marcaba de manera escultórica la entrada. El hall de acceso era un espacio abierto y fluido, perfectamente integrado en la naturaleza diseñada al exterior, gracias al uso de los pilotis de acero y su cerramiento en vidrio. Similar a la técnica tradicional en madera, Sakakura trabajaba la estructura metálica de pórticos perfectamente ordenados en una malla de orden que otorgaba serenidad al espacio. Abierto visualmente al exterior gracias a los grandes paños de vidrio que cerraban el conjunto, conectaba los diferentes espacios situados a cotas distintas a partir de una rampa que articulaba todo el conjunto. 

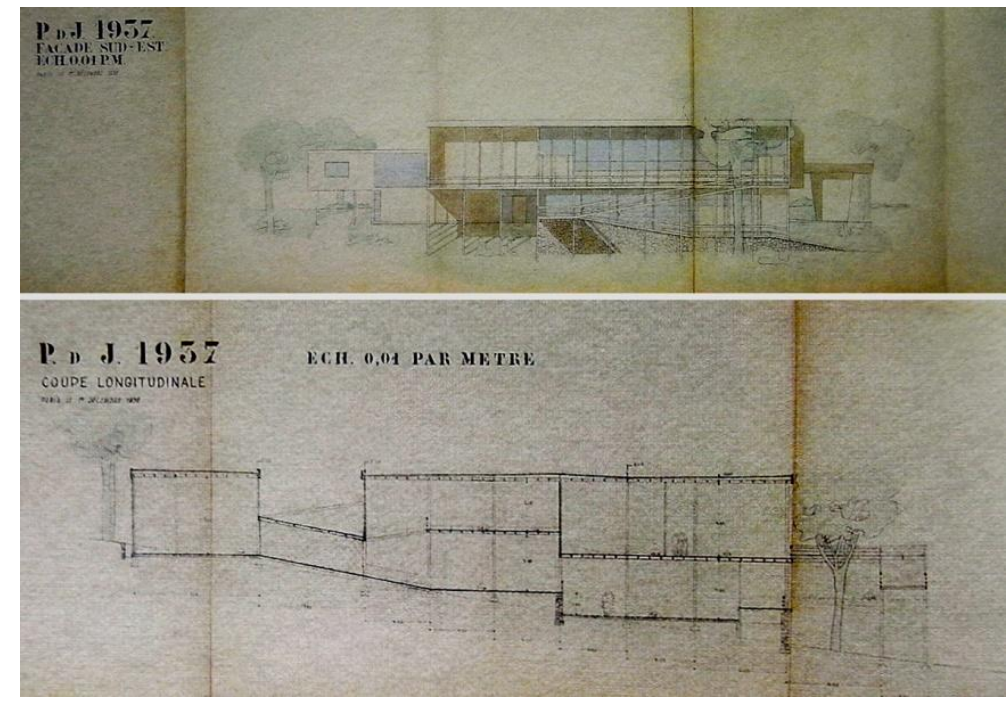

6. .Pavillon du Japon, 1937. Exposition Internationale des Arts et des Techniques Appliques a la Vie Moderne. Paris. Plano Original de alzado y sección. Montaje del autor.

Desde el hall de entrada, la rampa conectaba de manera autónoma con el volumen situado en la cota más elevada de la parcela, destinado a la exposición de las artes decorativas. Desde ahí, la rampa se desdoblaba para volver a ingresar en el edificio principal leyéndose, al estar cubierta, como un objeto independiente. El recorrido planteado por Sakaura que permitía salir al exterior para conectar un volumen diferente y luego volvía a entrar en el edificio principal, presentaba una celosía inspirada en el diseño del muro tradicional japonés denominado "namako kabe", aunque reinterpretado para conseguir un efecto de filtro muy permeable que permitiese el paso de luz, evocando los recorridos exteriores que conectaban los distintos pabellones de los templos tradicionales japoneses.

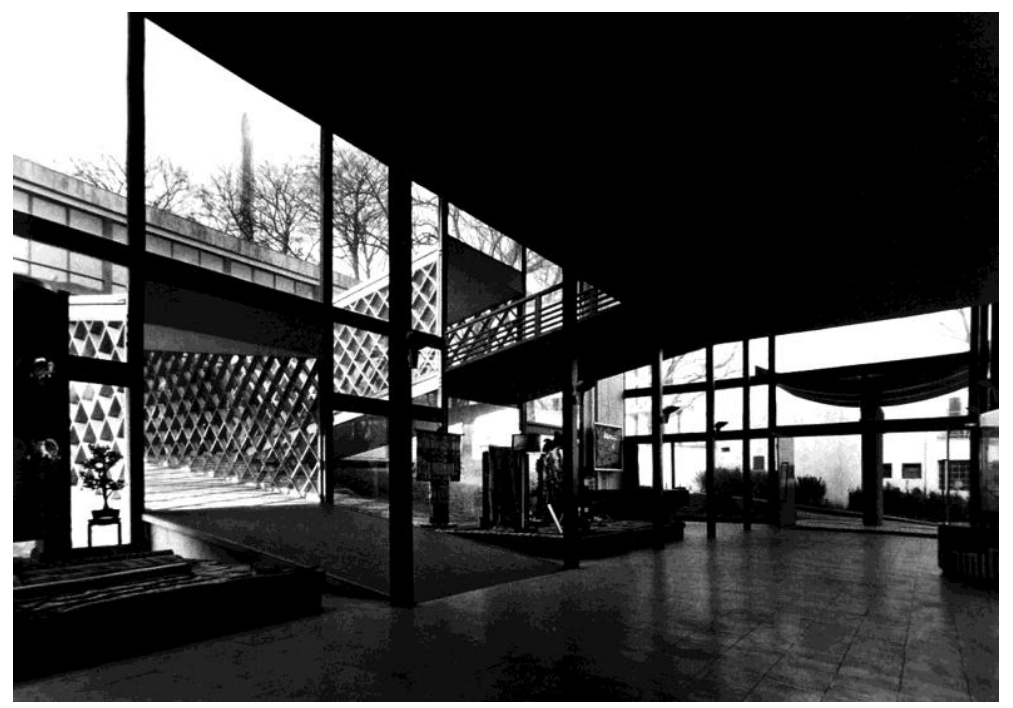

7. Japanese Pavilion, 1937. Paris International Exposition. Vista del interior del pabellón, con la rampa de acceso a la segunda planta.

Esa ida y vuelta de la rampa permitía capturar el espacio de los diferentes niveles de manera sucesiva, descubriendo cada estancia y sorprendiendo al espectador que recorría el pabellón para situarlo en el forjado superior, a cuyos lados se abría la planta baja, situándose a modo de pasarela sobre el hall. La planta alta guiaba al espectador por distintos niveles, conectados entre sí mediante la rampa, dentro de un espacio abierto y diáfano, 
cualificando cada estancia por la diferencia de cota. El empleo de estructura metálica, paneles de asbestocemento en zonas opacas y cerramiento de vidrio, hacía de esta arquitectura una construcción en seco liviana, etérea, que permitía un espacio fluido y continuo entre el interior y el exterior, ejemplificado en el diseño de la terraza mirador cubierta, a modo de porche, a la que se llegaba tras salir de la sala de propaganda. En una continuidad del recorrido que revelaba los espacios intersticiales tan interesantes en la arquitectura tradicional japonesa, y que enfatizaban el carácter tradicional al tamizar la luz mediante el empleo de unos toldos que emulaban el papel de arroz, este espacio disfrutaba de las vistas hacia el Sena y la Torre Eiffel, como fondo contemplativo reinterpretando el jardín japonés.

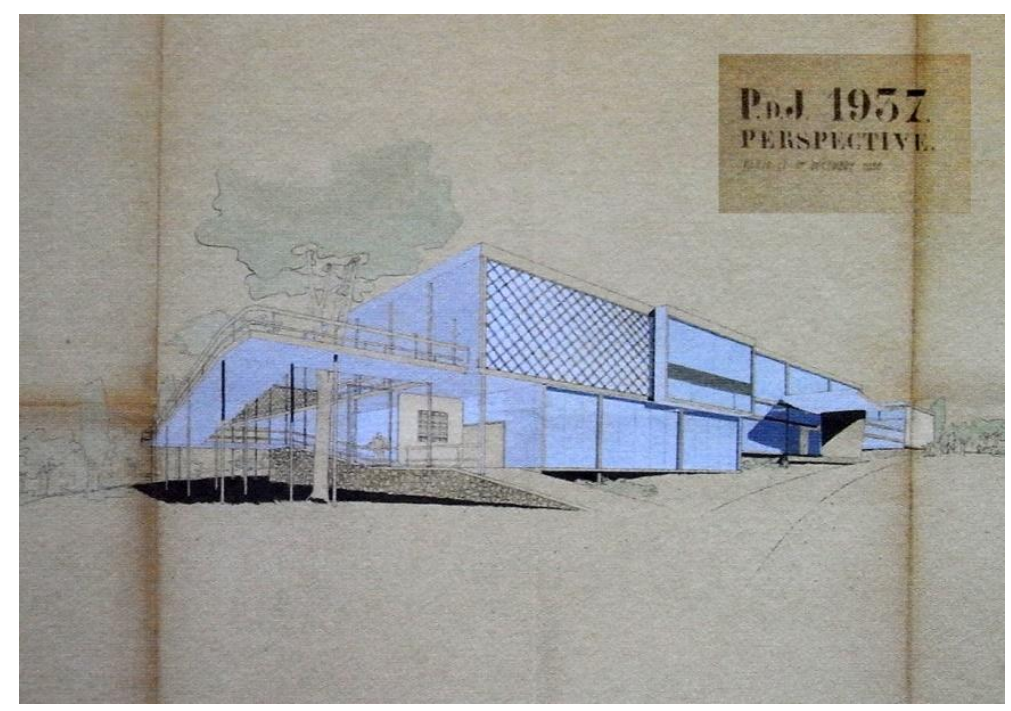

8. Pavillon du Japon, 1937. Exposition Internationale des Arts et des Techniques Appliques a la Vie Moderne. Paris. Plano Original de vista exterior en perspectiva. Montaje del autor.

El recorrido desde la terraza, situada en una cota privilegiada sobre la ladera de Trocadero, continuaba gracias a la rampa que articulaba el remate del proyecto en la fachada sureste. Separándose de la fachada cinco metros, y abrazando un árbol preexistente, descendía por el exterior hasta entrar nuevamente bajo la zona de terraza, a cubierto pero al exterior, para continuar el descenso hasta la cota de la sala de ciencias. El punto más deprimido de la actuación permitía solo a nivel espacial una visión global del conjunto del edificio para salir nuevamente a la rampa que nos acompañaba hasta el exterior del pabellón.

La memoria de proyecto de Sakakura ${ }^{7}$ justificaba la reinterpretación de la arquitectura tradicional japonesa en el edificio proyectado. La nueva arquitectura partía de la esencia del espacio y del estudio de las zonas de recorrido y zonas estanciales, asimilándolas a la articulación y composición de los elementos que conformaban el Palacio de Katsura.

Los recorridos y la interrelación con el paisaje aquí se diseñaban a partir de la rampa y la relación de las estancias con el jardín, tratando de captar la esencia de la tradición con un lenguaje arquitectónico adaptado a los nuevos tiempos.

\footnotetext{
7 Sakakura, Junzo: “Japanese Pavilion for the International Exhibition, Paris 1937”. En Gendai Kenchiku, Junio 1939, NN$^{\circ}$. Tokyo, 1939. Reeditado y traducido al inglés en Process: Architecture. "Sakakura Associates" May 1993, nº110. Tokyo: Process Architecture CO. Ldt. 1993. pp.32-34.
} 


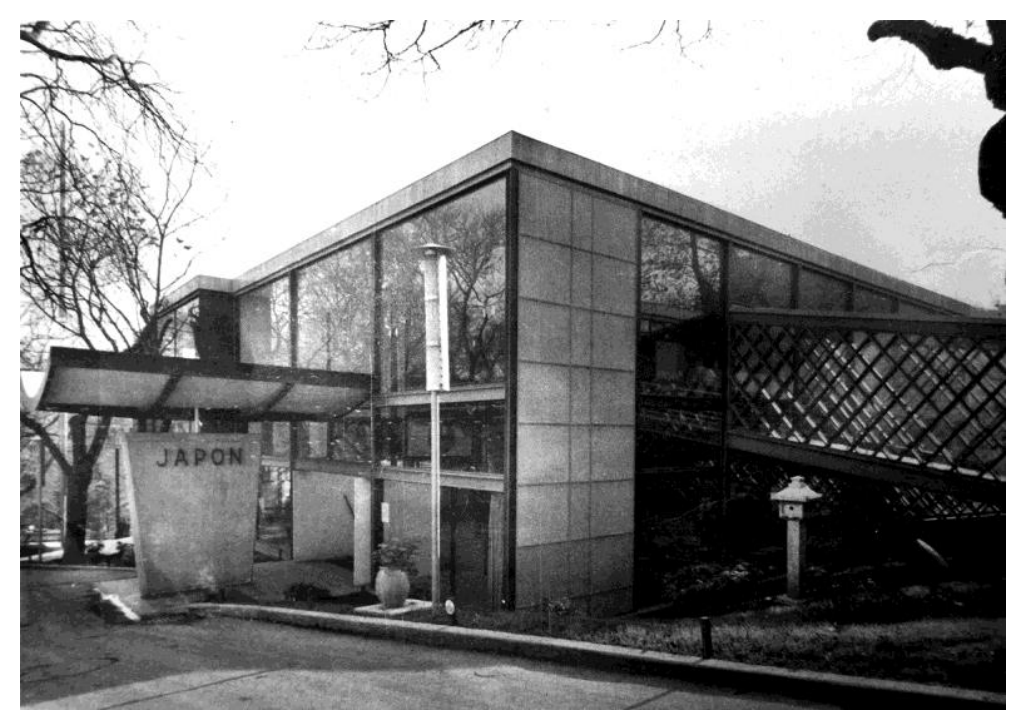

9. Japanese Pavilion, 1937. Paris International Exposition. Vista del exterior del pabellón, con la rampa de acceso a la segunda planta.

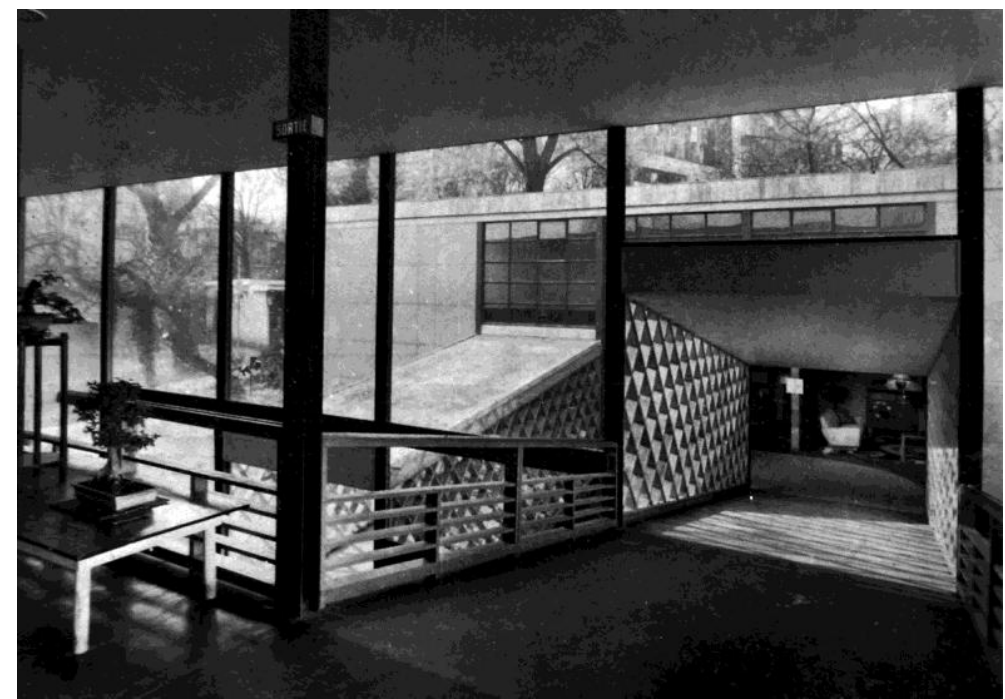

10. Japanese Pavilion, 1937. Paris International Exposition. Vista del interior del pabellón, desde el desembarco de la rampa en la segunda planta.

“La relación creada entre los espacios interiores y exteriores en el pabellón japonés para la Exposición de París de 1937 fue similar al sentimiento que produce cuando te sientas en el espacio conocido como "Koshoin" en el palacio de Katsura, mirando hacia el exterior, al lago, con los paneles shoji abiertos. En el pabellón japonés, sin embargo, los espacios estaban conectados por la pendiente exterior ${ }^{8, .}$

\footnotetext{
${ }^{8}$ Sakakura, Junzo: "Kamakura Museum of Modern Art”. En Kenchiku Bunka, Junio 1963, №6. Tokyo, 1963. Reeditado y traducido al inglés en Process: Architecture. "Sakakura Associates" May 1993, n¹10. Tokyo: Process Architecture CO. Ldt. 1993. pp.46.
} 


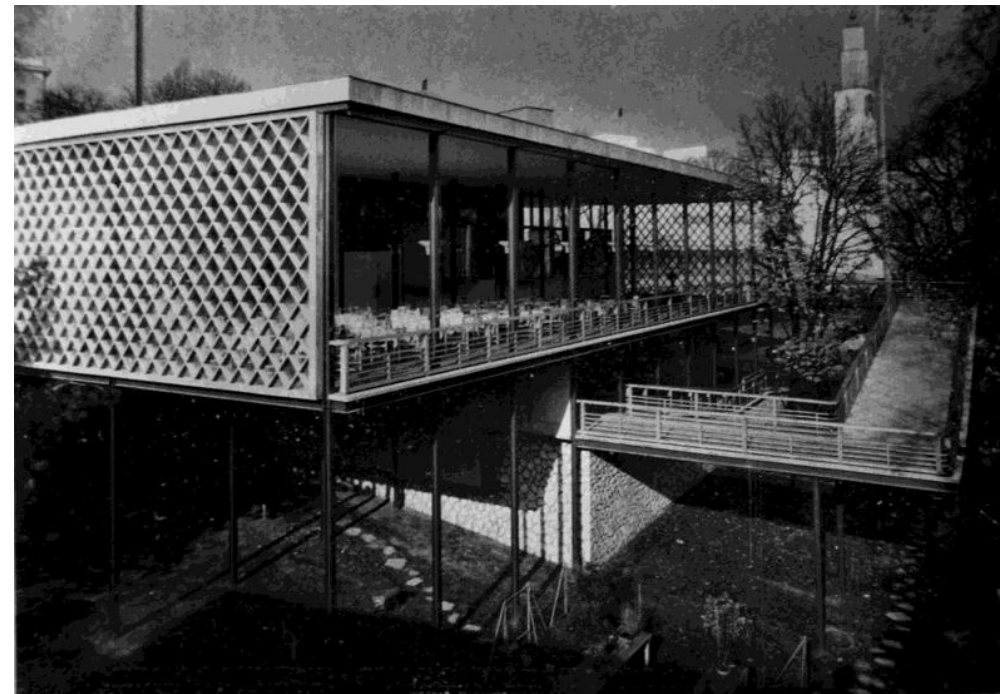

11. Japanese Pavilion, 1937. Paris International Exposition. Vista desde la terraza restaurante, con la rampa exterior de salida.

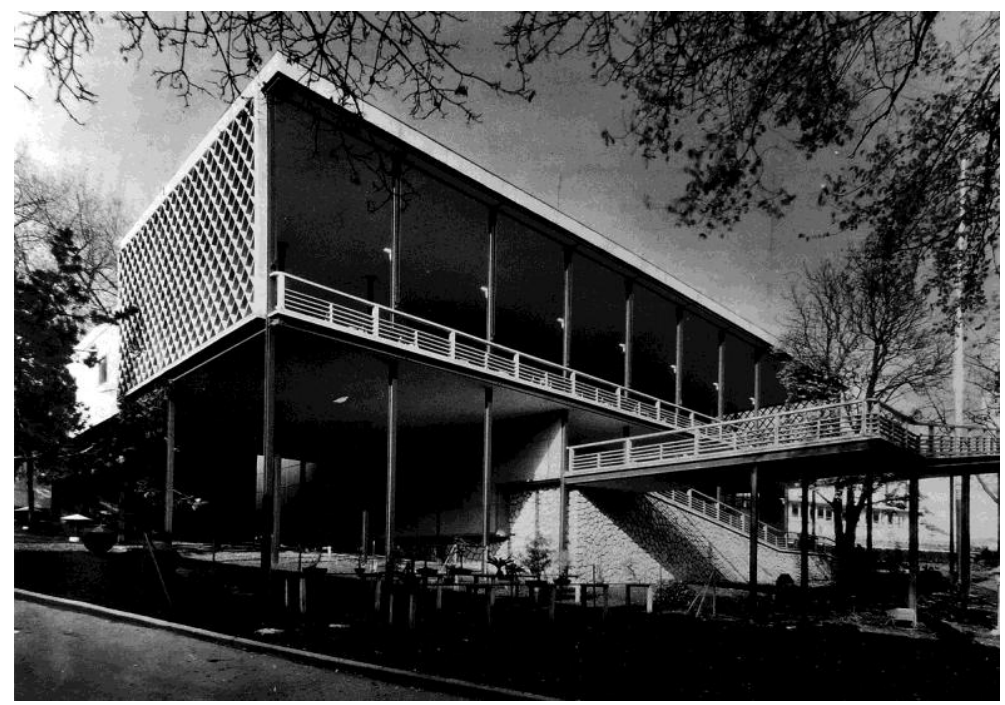

12. Japanese Pavilion, 1937. Paris International Exposition. Vista exterior del pabellón.

Esta visión del autor era compartida y reafirmada por la crítica que había captado la esencia de esta nueva arquitectura. Los comentarios de Giedion mostraban la importancia del recorrido para una clara definición de los espacios interiores y exteriores protagonizados por la rampa, entendiendo el logro que supuso la obra de Sakakura por su capacidad para armonizar modernidad y tradición a través de un nuevo lenguaje en arquitectura.

"A pesar de que todos los pabellones en la exhibición de París fueron construidos con un sentimiento de apertura, el pabellón de Japón es, probablemente, el más maravilloso. Las rampas que varían su pendiente pasan a través del centro del edificio, conectando cada parte y dirigiendo tanto al exterior como al interior. A pesar de tener habitaciones pequeñas, el hecho de que se encuentren unidas visualmente al jardín hacen que éste se pueda sentir más que cualquier otra cosa. Aunque el pabellón es occidental en estilo, logra 
completamente el sentido del espíritu japonés. El nombre del arquitecto que está en la treintena, Sakakura, debería ciertamente grabarse en nuestras mentes." S. Giedion ${ }^{9}$.

A pesar de los intentos por aunar a la modernidad la esencia de la arquitectura tradicional japonesa, el exceso de conservadurismo de los miembros del Comité, acostumbrados a una versión historicista de la arquitectura, produjo en ellos una reacción de descalificación al ver casi terminado el nuevo proyecto. Cuando la estructura fue tomando cuerpo y los volúmenes ya se adivinaban, los delegados japoneses se indignaron y criticaron nuevamente que el diseño no era típicamente japonés, apartando a Sakakura de las reuniones para definir el contenido expositivo del pabellón. La selección del diseño del interior del pabellón y su exhibición corrió a cabo de los representantes del Ministerio de Comercio y del Comité para la Exposición de París, que expusieron la versión más rancia y tradicional de la cultura japonesa que poco tenía que ver con el verdadero objetivo de la exposición “Arte y Tecnología en la Vida Moderna”.

Cuando Sakakura vio la exhibición que habían montado, deploró la forma en que halagaban a Europa occidental mientras le prohibían formar parte de las reuniones para determinar qué objetos formarían parte de la exposición. El resultado, lógicamente, mostraba un exagerado contraste entre el continente -un pabellón moderno y avanzado- y el contenido, - de marcado carácter tradicional- dando un resultado incoherente que entendió muy bien Giedion, cuando en su crítica para el semanario Die Weltwoche comentaba que los japoneses tenían que estar muy agradecidos a Sakakura, "por evitar que Japón fuera el hazmerreír de la exposición, al llenar el interior del pabellón con un torpe simulacro de muebles, basura para las tiendas europeas, y por la inconsistencia mostrada por el conjunto de inventos exagerados y poco armoniosos que no podían igualar la calidad del propio edificio" ${ }^{\text {, }}$, coincidiendo con los comentarios de H.R. Hitchcock para Architectural Forum a propósito del desastre de la exposición presentada por Japón a pesar del excelente resultado formal de su pabellón $^{11}$.

El pabellón japonés fue terminado a principios de Junio, en medio de un clima de crispación interna, pero una vez abierto al público el edificio fue objeto de las mejores críticas y elogios de gran parte de los arquitectos venidos de todas las partes del mundo.

\section{Dos proyectos, un maestro.}

“El sentimiento moderno es un espíritu de geometría, un espíritu de construcción y de síntesis".

Le Corbusier ${ }^{12}$.

\subsection{Un discípulo a distancia.}

Kunio Mayekawa había trabajado en el estudio de Le Corbusier desde 1928 a 1930. Durante esa época, además de trabajar en proyectos como la Ville d'Avray, el Centrosoyus de Moscú, el Salon d'Automne ${ }^{13}$, los estudios

\footnotetext{
${ }^{9}$ Giedion, Sigfried: “Paris Exhibition, 1937”. En Die Weltwoche, 1937. Recogido en Gendai Kenchiku, Junio $1939, \mathrm{~N}^{\circ} 1$. Tokyo, 1939. pp. 12.

${ }^{10}$ Giedion, Sigfried: "Paris Exhibition, 1937”. En Die Weltwoche, 1937. Recogido en Gendai Kenchiku, June $1939, \mathrm{~N}^{\circ} 1$. Tokyo, 1939. pp. 12.

${ }^{11}$ Hitchcock, Henry Rusell: "Paris Exposition, 1937”. En Architectural Forum, September 1937, Vol.67 No3. New York: Ed. Time Inc. 1937. pp. 173.

${ }^{12}$ Le Corbusier; Jeanneret, Pierre: Le Corbusier et Pierre Jeanneret. Oeuvre Complète 1910-1929. Zurich: Publiée par Willy Boesiger, 1964. pp. 97.

${ }^{13}$ Donde colaboró en el diseño y fabricación del mobiliario creado por Le Corbusier, Jeanneret y Charlotte Perriand.
} 
iniciales para el concurso del Palacio de los Soviets de Moscú, y sobre todo la construcción de la Villa Saboye, participaría en el II CIAM de 1929 acompañando a Le Corbusier, y visitaría junto al maestro la WeissenhofSiedlung de Stuttgart, analizado los fundamentos de la vivienda mínima ${ }^{14}$ que le servirán en los años posteriores a la Segunda Guerra Mundial como base para iniciar el camino de la reconstrucción de Japón. En paralelo a su trabajo en el despacho, Mayekawa se presentaba a concursos convocados en su país a título personal. No es de extrañar que algunos de estos proyectos tuvieran reminiscencias de los proyectos realizados por Le Corbusier, como el Nagoya City Hall, del que tomará como referencia el Centrosoyus de Moscú. El desarrollo del concurso para el pabellón de Japón fue realizado en 1936 en su propio despacho, tras haber regresado de París y haber trabajado para A. Raymond hasta 1935. Para su diseño, Mayekawa tomó como referencia un antiguo proyecto que le sirvió para obtener su titulación, trabajándolo y adaptándolo a las nuevas necesidades requeridas por el concurso.

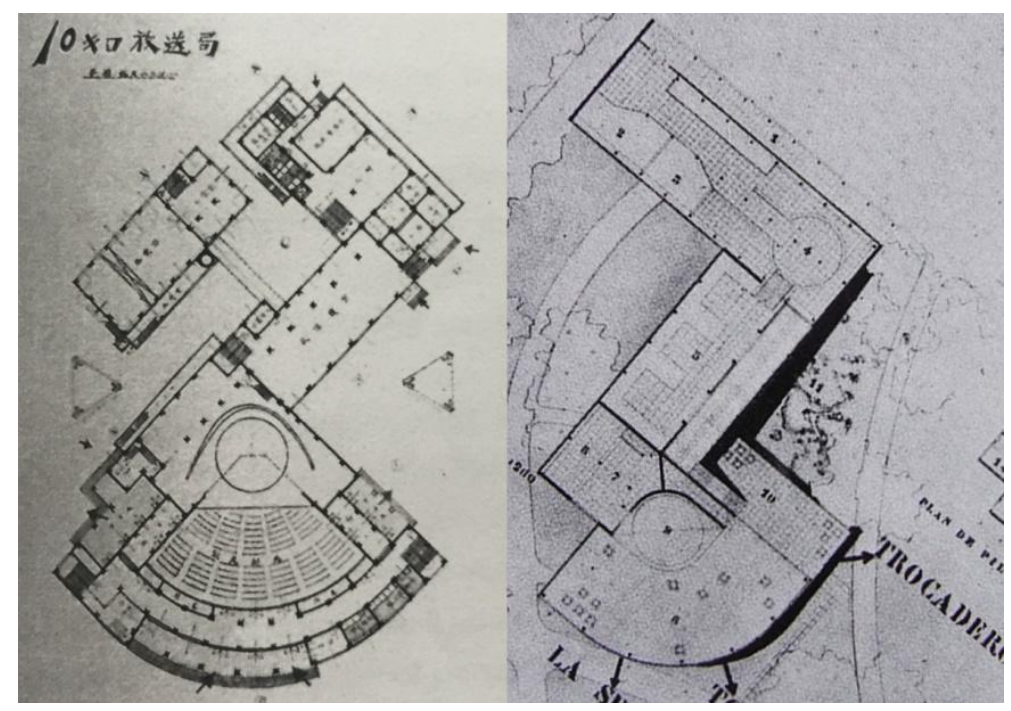

13. Comparativa entre el proyecto de graduación y el proyecto del pabellón. Montaje del autor.

Este proyecto había tenido como inspiración inicial algunos de los proyectos publicados en la revista L'Architecture Vivante ${ }^{15}$, como el Palacio del Trabajo de los hermanos Vesnín -con una forma curva muy particular que Mayekawa reinterpretaba para culminar su intervención-, o el Palacio para la Liga de las Naciones de Le Corbusier, cuyos volúmenes se articulaban e independizaban de acuerdo a su función, generando unos espacios interiores y exteriores a través de la propia geometría. Volumétricamente, el edificio para la graduación y el edificio del concurso presentaban numerosas similitudes, como la articulación de los cuerpos de acceso situados en perpendicular, y el anexo de sector circular que completaba el conjunto de manera idéntica al planteamiento de la sala de espectáculo. Además su circulación interior se desarrollaba de la misma manera, con la diferencia de que al asentarse sobre un terreno con topografía accidentada necesitaba conectar los distintos volúmenes mediante escaleras para generar la transición entre los distintos espacios. Sorprende que habiendo estado trabajando en la Villa Saboya, donde las circulaciones y el recorrido se organizaban en torno a una rampa que podría conectar todos los espacios expositivos de manera continua, Mayekawa planteara una jerarquía de

\footnotetext{
${ }^{14}$ Hiroshi, Matsukuma: "The Pursuits of Kunio Mayekawa. The Revitalization of Modern Architecture". The Exhibition Organizing Committee for Kunio Maekawa Retrospective (ed): The Work of Kunio Maekawa: A Pioneer of Japanese Modern Architecture. Tokyo: Bijutsu shuppansha, 2006. pp 303-305

${ }^{15}$ Reynolds, Jonathan M.: Maekawa Kunio and the Emergence of Japanese Modernist Architecture. Berkeley: University of California Press, 2001. pp. 52-54.
} 
niveles, adaptados a la topografía pero conectados mediante escaleras. En el proyecto de concurso buscaba una relación con el exterior, creando los porches, que modificaban sustancialmente la imagen de los huecos retranqueados de la fachada de pilotis que cerraba el conjunto. La ausencia de detalles historicistas, la aparición de una planta libre sobre pilotis, ventanas corridas y fachadas libres acercaban la propuesta a las ideas de Le Corbusier.

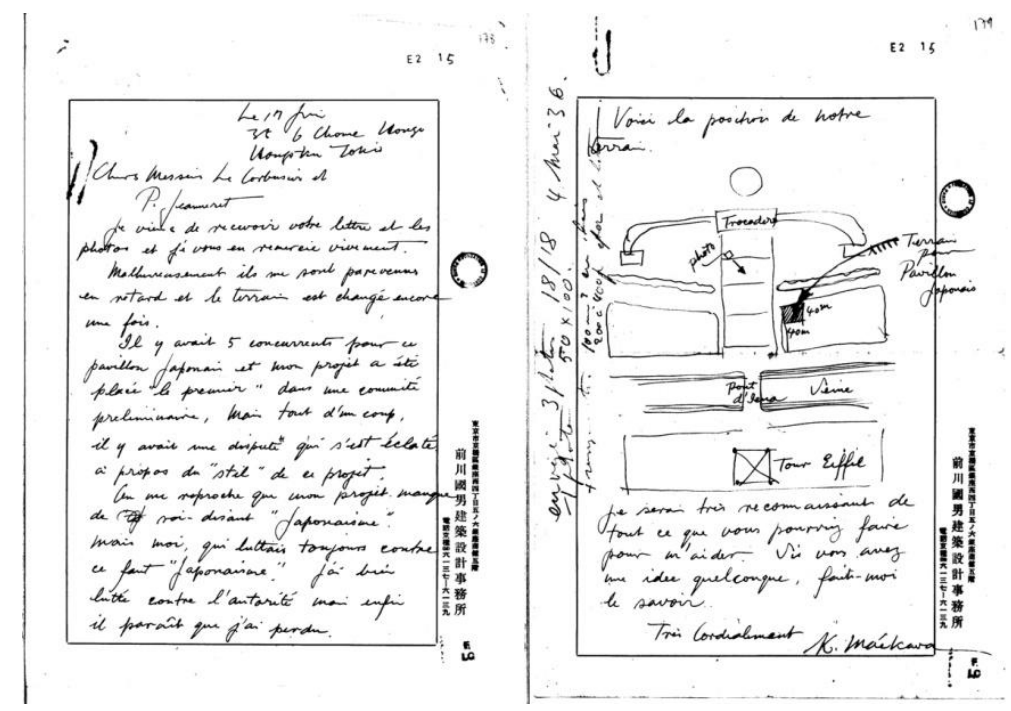

14. Carta enviada por Mayekawa a Le Corbusier, donde le comenta los problemas de "estilo poco japonés" de la propuesta. Se detalla aquí la primera ubicación propuesta para el pabellón.

El volumen curvo sobre pilotis mostraba una imagen conceptualmente similar a la Villa Saboye, separándose del suelo para conseguir un plano de estancia elevado, desde el que dominar el paisaje. Las ideas materializadas en el Pabellón de L’Esprit Nouveau eran conocidas por Mayekawa, acentuadas por el interés en el capítulo “Confesiones" del libro L'Art Décoratif d'aujourd'hui, que había cambiado su percepción de la arquitectura, motivándole a trabajar con Le Corbusier ${ }^{16}$. Sin embargo, para el diseño de este concurso Mayekawa prefería continuar con sus propias investigaciones en arquitectura, partiendo del conocimiento adquirido en París, pero evolucionando y adaptando las ideas aprendidas de su maestro a su propia cultura. El pabellón de Japón para la Exposición de París en 1937, ejemplificaba a la perfeccción la actitud de Mayekawa, que buscaba su propio camino a través de la arquitectura, pero mostrando un profundo respeto a su maestro y compartiendo con él mediante correspondencia las dudas, inquietudes, y las fotografías de la propuesta presentada al concurso para conocer su opinión ${ }^{17}$.

\footnotetext{
${ }^{16}$ Según palabras de Mayekawa en su edición del libro L’Art Decoratif d’Aujourd'hui en japonés. En Yuzuru, Tominaga: "Exploring the Ethical Spirit of Modern Architecture". The Exhibition Organizing Committee for Kunio Maekawa Retrospective (ed): The Work of Kunio Maekawa: A Pioneer of Japanese Modern Architecture. Tokyo: Bijutsu shuppansha, 2006. pp 305.

${ }^{17}$ Correspondencia entre Mayekawa y Le Corbusier: Fundación Le Corbusier, E2-15 (174), 1936. Envío de fotografías tomadas de la propuesta presentada al concurso.
} 


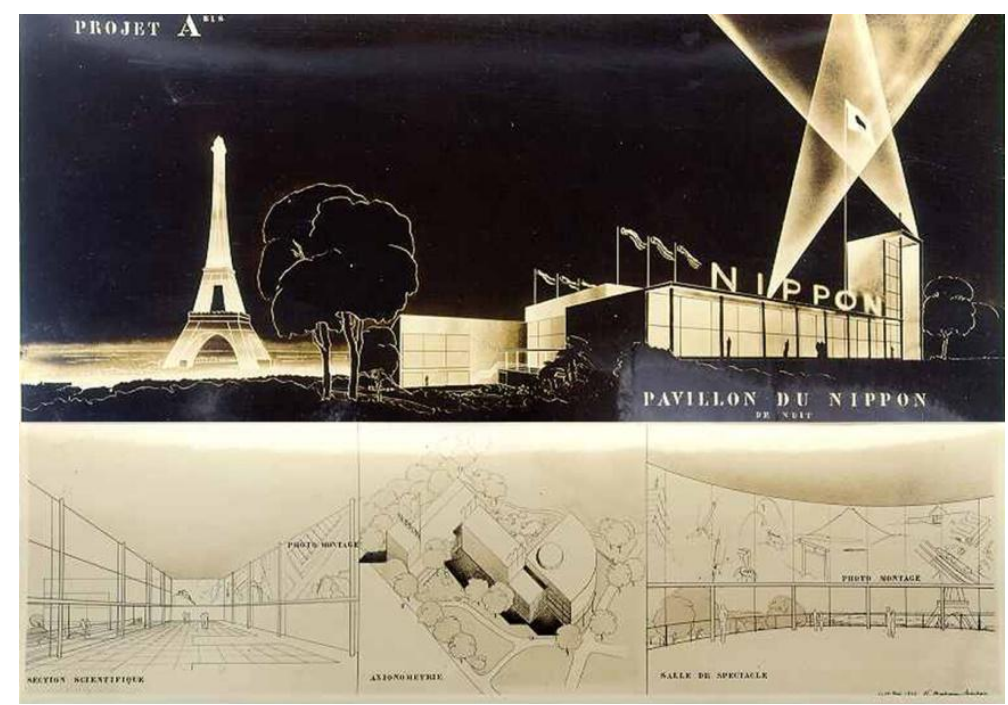

15. Pavillon du Nippon. 1937. Fotografías de la propuesta presentada a concurso enviada por Mayekawa a Le Corbusier. Montaje del autor.

Él mismo comentaba en una entrevista publicada en 1937: "la gente me pregunta: tú fuiste discípulo de Le Corbusier, ¿verdad?. Entonces, ¿por qué no construyes casas que parezcan las de Le Corbusier?. Me sentí honrado de tales comentarios. Sin embargo, durante los dos años que estuve en el estudio de Le Corbusier, él me enseñó, precisamente, a no cometer sus mismos errores" ${ }^{\text {"18 }}$ Y es que, como muy bien comenta Hiroshi Yamaguchi, "Mayekawa nos descubrió la posición de un arquitecto que, desafiando la verdadera esencia de la arquitectura moderna de Le Corbusier, supo encontrar su propio camino como arquitecto" 19 en el contexto de la compleja cultura japonesa, con la referencia clara de un maestro del cual aprender, para crecer, evolucionar y desarrollarse.

\subsection{Un discípulo al lado del maestro.}

El proyecto de Sakakura, a diferencia del anterior, se desarrolló no a 10.000 kilómetros de distancia, sino en el mismo estudio de la calle Sèvres. La proximidad y cercanía se aprecia durante toda la fase de diseño del proyecto y sobre todo durante la fase de ejecución, ya que Le Corbusier construye para la Exposición Internacional el Pabellón de los Nuevos Tiempos y era habitual la visita de obra a ambos pabellones junto a su pupilo Sakakura.

El paralelismo que se puede observar entre los dos pabellones es sustancial atendiendo al concepto de circulación y organización espacial de los recorridos mediante la rampa. Ésta ya había sido estudiada para este tipo de espacios expositivos en la Villa La Roche ${ }^{20}$, donde Le Corbusier permite una percepción graduada de la colección de pintura que cuelga de la pared. Para una exposición, organizar los distintos espacios a partir del

\footnotetext{
18 Mayekawa, Kunio: “Comentarios”. En Mokuyokai Zasshi, December 1937. Tokyo: Tokyo University. 1937. pp. 14. Recogido al inglés en Yuzuru, Tominaga: "Exploring the Ethical Spirit of Modern Architecture". ". The Exhibition Organizing Committee for Kunio Maekawa Retrospective (ed): The Work of Kunio Maekawa: A Pioneer of Japanese Modern Architecture. Tokyo: Bijutsu shuppansha, 2006. pp 302.

${ }^{19}$ Hiroshi, Yamaguchi: "Kunio Mayekawa and Japanese Modern Architecture". The Exhibition Organizing Committee for Kunio Maekawa Retrospective (ed): The Work of Kunio Maekawa: A Pioneer of Japanese Modern Architecture. Tokyo: Bijutsu shuppansha, 2006. pp 302.

${ }^{20}$ Quetglas, Josep: “Promenade Architecturale”. En Web Architecture Magazine. №5 Ediciones Actar. Internet Editor: Yes.
} 
recorrido continuo que ofrece un rampa sería una buena solución. También la experimentación de los recorridos en la Villa Saboye supone un punto de influencia en Sakakura, al interpretar la secuencia de espacios a partir de los puntos de arranque y desembarco de la rampa, la organización de los sentidos de ascenso en ida y vuelta para leer por completo el edificio en una "promenade architecturale", y sobre todo a partir del empleo de la rampa para conectar espacios interiores, exteriores y de transición, abiertos al jardín.

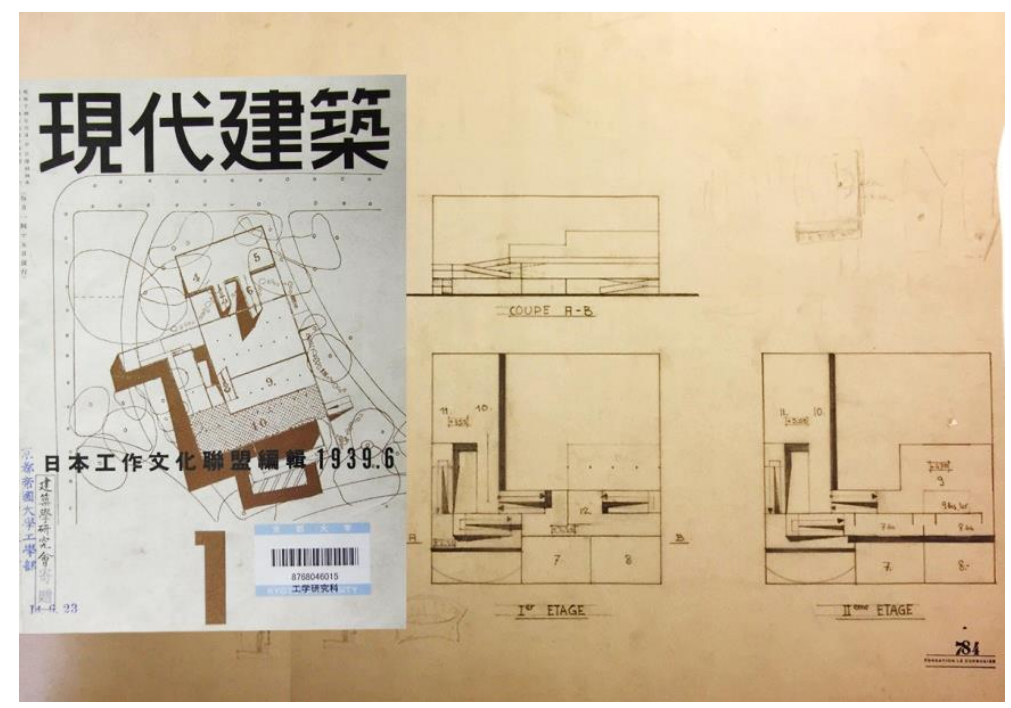

16. Esquema de circulaciones en los pabellones de Japón y de los Nuevos Tiempos. Montaje del autor.

Éste es el planteamiento que utiliza Sakakura sacando el máximo partido a la pendiente del solar para establecer las conexiones de su pabellón, utilizando la rampa no solo como medio de comunicación, sino como elemento escultórico en sí mismo, que permite desde la terraza de la planta superior aparecer como un objeto autónomo que sale al exterior, abraza la vegetación, gira y desciende para cobijarse bajo el forjado mientras se recorre el jardín, nos introduce nuevamente en el pabellón para mostrar la zona de ciencia, llevándonos -a través de este paseo continuo- por todos los espacios expositivos hasta la salida del pabellón.

El criterio estaba en sintonía al utilizado por Le Corbusier para el Pabellón de los Nuevos Tiempos, que necesitaba de la rampa para establecer un recorrido continuo a través de las diversas zonas expositivas variando su cota, introduciendo al espectador en un montaje ensimismado desde el que mostrar sus ideas urbanísticas a partir de la "promenade architecturale".

La lectura de las circulaciones es entendida muy bien por la crítica, con los comentarios de Giedion y H.R. Hitchcock que se estudiaban con anterioridad, y por la crónica de Chermayeff para la revista Architectural Review, donde establecía el paralelismo de las actuaciones de Sakakura y Le Corbusier en base a la circulación que proponían en ambos pabellones. Con el título "Circulación: diseñar: exhibir. El arquitecto en la Exposición”, Chermayeff hacía una especial mención al pabellón japonés comentando que "las características nacionales prevalecen, a pesar de que surgieran de una curiosa influencia Japón- vía Europa- vía Japón. La elegancia japonesa de la construcción en madera aquí se expresa a través del acero”. Afinando su análisis, más adelante relacionaba al discípulo con el maestro al afirmar que "ambos, Le Corbusier y su último pupilo Sakakura, han actuado bajo el dictado de Le Corbusier de que "las escaleras son enemigas de lo público" y han empleado exclusivamente rampas. [...] Mientras Le Corbusier usa rampas como parte de la exhibición del espacio, Sakakura, francamente, las trata sólo como un medio de comunicación entre elementos claramente separados 
por la estructura, finalizando con una rampa de salida desde el restaurante situada lógica y simplemente fuera de su edificio pero integrada deliciosamente en el diseño del jardin. "21

El espacio de exhibición del pabellón de Japón era rico en cuanto a la disposición de dobles alturas, pasarelas y continuidades visuales, con un patrón de flujo de circulación, que estaba en armonía con el entorno y los jardines diseñados al exterior. En contra del análisis efectuado por Chermayeff, la rampa no parece que fuera sólo un "medio de comunicación entre elementos", sino el medio para crear una "promenade" necesaria para entender la configuración espacial de la actuación, justificando la disposición sobre la ladera de la colina, jerarquizando los espacios para ofrecer al espectador un recorrido expositivo en una fruición espacial.

La selección de un método constructivo novedoso con estructura metálica y el empleo de nuevos materiales como acero, vidrio y los paneles de asbesto-cemento eran conocidos por Sakakura, que ya los había trabajado en los proyectos del estudio de Le Corbusier. El único problema que le causaba alguna ansiedad era el detalle. Consciente de la importancia, redibujó una y otra vez las barandillas y la rampa, así como la marquesina de la entrada, que le estaba dando numerosos problemas en su composición.

La anécdota de la influencia de Le Corbusier en el diseño del pabellón la comentaba el propio Sakakura, cuando su maestro, al verle en dificultades para diseñar la entrada, se acercó y le preguntó "¿en Japón no tenéis también líneas curvas como los torii sintoístas?”22 y dibujándole un croquis contribuyó a dar ese toque de genialidad a la entrada sintetizando la esencia japonesa, tal y como haría años después en India al captar el espíritu de lo sagrado para reinterpretarlo en su arquitectura.

Las visitas de obra junto a Le Corbusier también contribuyeron a matizar la imagen del edificio. Queda constancia del comentario que hizo a Sakakura cuando el muro trasero del pabellón fue pintado con los colores pasteles de las cortinas de teatro kabuki, que a ojos del maestro "no eran ni de un sitio ni de otro"23 animándolo a usar colores brillantes, que fue la decisión que primó al final.

\footnotetext{
${ }^{21}$ Chermayeff, Serge: “Circulation: design: display. The architect at the exhibition”. En Architectura Review. Vol. 82, №488. July. 1937. pp. 91-104.

${ }^{22}$ Tadayoshi, Fujiki: “Tokyo-Paris 1936-1937”. En Process: Architecture. "Sakakura Associates” May 1993, n¹10. Tokyo: Process Architecture CO. Ldt. 1993. pp.36.

${ }^{23}$ Tadayoshi, Fujiki: "Tokyo-Paris 1936-1937”. En Process: Architecture. "Sakakura Associates" May 1993, n¹10. Tokyo: Process Architecture CO. Ldt. 1993. pp.37.
} 


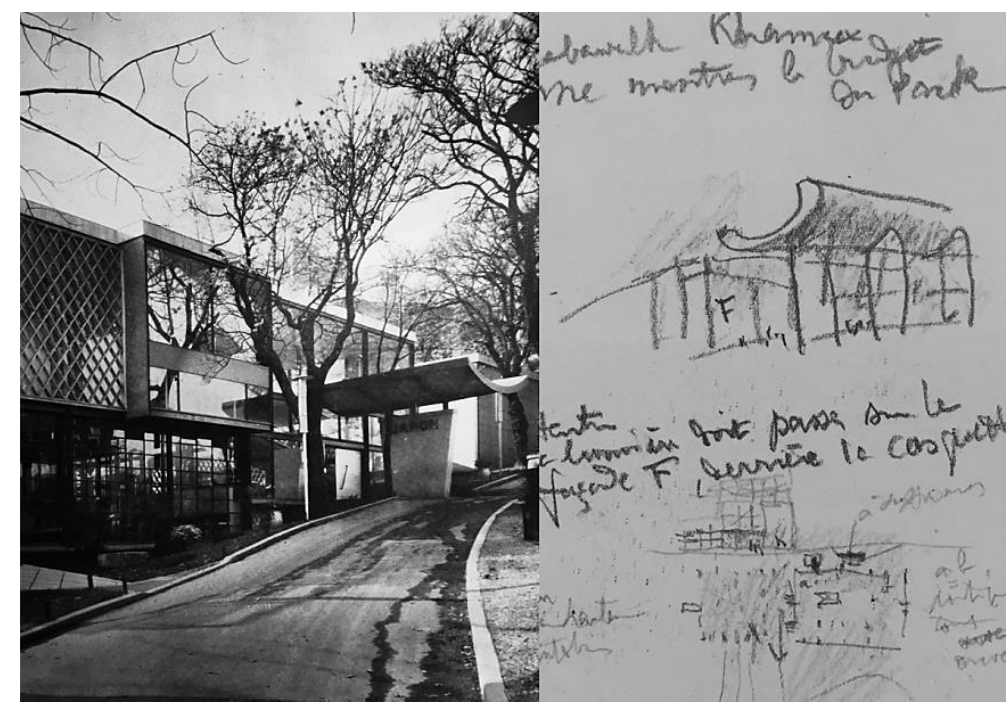

17. Comparativa entre la pérgola de entrada al pabellón y dibujo de Le Corbusier para India. Montaje del autor.

En un artículo escrito para la revista Gendai Kenchiku ${ }^{24}$ que acompañaba a la publicación del Pabellón de Japón en París unos años después, Junzo Sakakura exponía las nuevas ideas sobre arquitectura que habían influenciado en la construcción del pabellón, justificando su actuación en base a los criterios de la exposición, que trataban sobre el "Arte y la Tecnología en la Vida Moderna". Entre sus comentarios, explicaba cómo la máxima corbuseriana de "la casa es una máquina de habitar" no había sido bien interpretada en Japón, porque la palabra "máquina" se refería al diseño, a los logros de la ciencia moderna y de la tecnología; y "habitar" al hecho de ser vivida. La casa era diseñada según los logros tecnológicos de una época con el propósito de vivirla. Este sentido de vivir el espacio es lo que Le Corbusier le había transmitido y lo que Sakakura pretendía mostrar con su pabellón: una construcción capaz de mostrar los avances tecnológicos de una época que pudiese ser vivida, donde el visitante se sintiera inmerso en un recorrido a través de la cultura japonesa, no solo por los materiales expuestos, sino por la propia arquitectura - capaz de aunar la modernidad con la esencia de la tradición de los palacios imperiales o los jardines-. En sus propias palabras el Pabellón de Japón para la exposición de París de 1937 fue "la manera de expresar mediante la obra construida lo que entendía que debía ser la nueva arquitectura en Japón, y cómo debía desarrollarse en un futuro."25

\section{Conclusiones}

Hoy, estudiando este proyecto desde la distancia, podemos hacer dos lecturas diferentes a partir de las dos propuestas presentadas - la ganadora del concurso y la ejecutada - teniendo en cuenta la influencia y puntos de contacto de sus autores con el maestro. Esta relación, que se refleja en la arquitectura del pabellón, nos muestra los caminos de dos discípulos de Le Corbusier, que partiendo de un mismo origen -el estudio de la calle Sèvresofrecen dos soluciones distintas, derivadas de dos respuestas personales distintas.

Por un lado Mayekawa, que nos descubrió la posición de un arquitecto que, desafiando la verdadera esencia de la arquitectura moderna de Le Corbusier, supo encontrar su propio camino en el contexto de la cultura japonesa.

\footnotetext{
${ }^{24}$ Sakakura, Junzo: “Japanese Pavilion for the International Exhibition, Paris 1937”. En Gendai Kenchiku, Junio 1939, №1. $^{\circ}$ Tokyo, 1939. pp. 10-11.

${ }^{25}$ Sakakura, Junzo: “Japanese Pavilion for the International Exhibition, Paris 1937”. En Gendai Kenchiku, Junio 1939, NN$^{\circ}$. Tokyo, 1939. pp. 10.
} 
Por otro lado Sakakura, que de la mano del maestro, aprendió a armonizar la tradición y la modernidad, interiorizando un profundo conocimiento del espacio y de los recorridos que recordaban la disposición del Palacio de Katsura frente a las propuestas para la Villa Saboya o el Pabellón de los Nuevos Tiempos de Le Corbusier.

Las dos propuestas, a pesar de sus diferencias, son extremadamente coherentes con la temática propuesta para la exposición “Arte y Técnica de la Vida Moderna”, y con los planteamientos teóricos desarrollados siguiendo las enseñanzas de Le Corbusier. Aunque siempre quedará la obra construida, el Pabellón Japonés para la Exposición de París de 1937, que alzándose con uno de los premios de arquitectura otorgados por la federación francesa junto con el pabellón de Finlandia de Aalto y con el pabellón de España de Jose Luis Sert-, fue capaz de colocar por primera vez a Japón en la escena internacional, a la vanguardia de la arquitectura moderna.

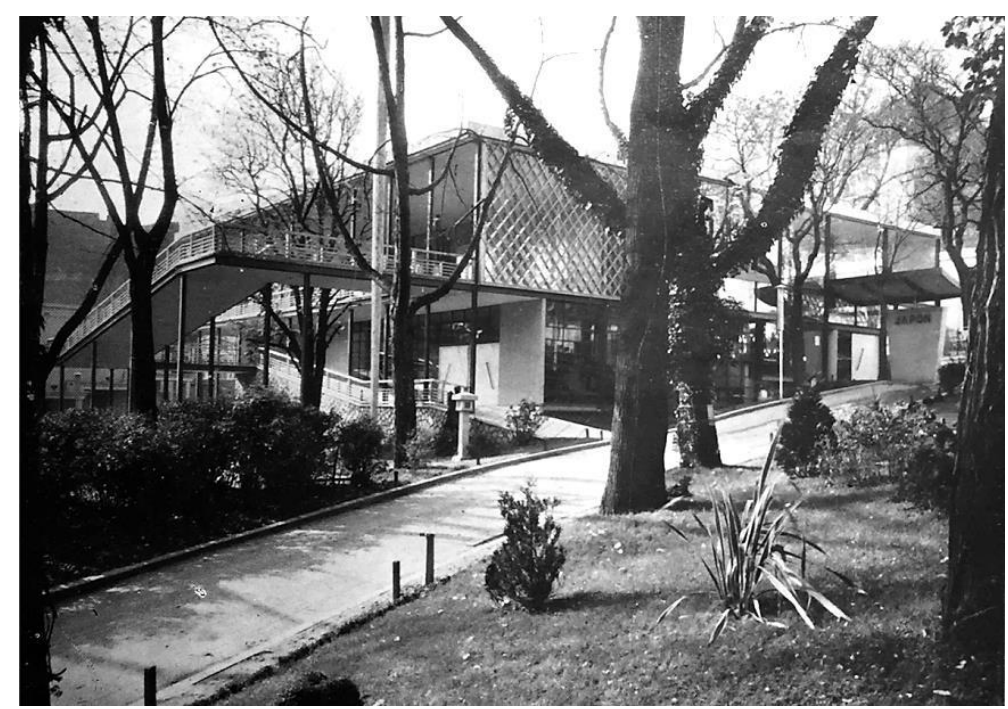

18. Pabellón de Japón, 1937. Vista desde el sur, con el acceso, la terraza restaurante y la rampa exterior de salida.

\section{Agradecimientos}

Departamento Proyectos Arquitectónicos. Cátedra Blanca CEMEX - Grupo Investigación Cultura del Hábitat. ETSAM. Universidad Politécnica de Madrid. (España).

Architecture and Design Department. Arai Lab. Kyoto Seika University. Kyoto (Japón).

\section{Procedencia de las imágenes}

Imagen 1. Pavillon du Nippon. 1937. Fondation Le Corbusier, Paris. E2-15. 182-004. CFLC-ADAGP

Imagen 2. Kokusai Kenchiku 12, nº. Septiembre 1936. Tokyo.

Imagen 3. Kokusai Kenchiku 12, nº9. Septiembre 1936. Tokyo.

Imagen 4. Kokusai Kenchiku 12, nº. Septiembre 1936. Tokyo.

Imagen 5. Junzo Sakakura Architect. Kamakura:Kenchiku Shiryo Kenkyusya, 2010.

Imagen 6. Junzo Sakakura Architect. Kamakura:Kenchiku Shiryo Kenkyusya, 2010.

Imagen 7. Gendai Kenchiku, No1. Junio 1939. Tokyo, 1939.

Imagen 8. Junzo Sakakura Architect. Kamakura:Kenchiku Shiryo Kenkyusya, 2010.

Imagen 9. Gendai Kenchiku, №1. Junio 1939. Tokyo, 1939. 
Imagen 10. Gendai Kenchiku, Nº1. Junio 1939. Tokyo, 1939.

Imagen 11. Gendai Kenchiku, Nº1. Junio 1939. Tokyo, 1939.

Imagen 12. Process: Architecture. Nº110. May 1993. Tokyo: Process Architecture CO. Ldt. 1993.

Imagen 13. The Work of Kunio Mayekawa, a Pioneer of Japanese Modern Architecture, Tokyo: BSS, 2006.

Imagen 14. Fondation Le Corbusier, Paris. E2-15. 178-179.

Imagen 15. Fondation Le Corbusier, Paris. E2-15. 182-005 y 182-006.

Imagen 16. Gendai Kenchiku, Nº1. June 1939. Tokyo. Fondation Le Corbusier, Paris. 784 CFLC-ADAGP

Imagen 17. Gendai Kenchiku, Nº1. June 1939. Tokyo. Fondation Le Corbusier, Paris. K-41, 571 @FLC-ADAGP

Imagen 18. Gendai Kenchiku, Nº1. Junio 1939. Tokyo, 1939.

\section{Bibliografía}

Architectural Forum. Vol.67, N³. September 1937,. New York: Ed. Time Inc. 1937.

Architectural Review. Vol. 82, N488. July 1937.

Chermayeff, Serge: “Circulation: design: display. The architect at the exhibition". En Architectural Review. Vol. 82, No488. July. 1937. pp. 91-104.

Gendai Kenchiku, Nº1. Junio 1939. Tokyo, 1939.

Giedion, Sigfried: “Paris Exhibition, 1937”. En Die Weltwoche, 1937. Recogido en Gendai Kenchiku, №1. Junio 1939,. Tokyo, 1939. pp. 12.

Hitchcock, Henry Rusell: "Paris Exposition, 1937”. En Architectural Forum, Vol.67. N³. September 1937, New York: Ed. Time Inc. 1937. pp. 173.

Hiroshi, Matsukuma: "The Pursuits of Kunio Mayekawa. The Revitalization of Modern Architecture". The Exhibition Organizing Committee for Kunio Maekawa Retrospective (ed): The Work of Kunio Maekawa: A Pioneer of Japanese Modern Architecture. Tokyo: Bijutsu shuppansha, 2006. pp 303-305

Hiroshi, Yamaguchi: "Kunio Mayekawa and Japanese Modern Architecture". The Exhibition Organizing Committee for Kunio Maekawa Retrospective (ed): The Work of Kunio Maekawa: A Pioneer of Japanese Modern Architecture. Tokyo: Bijutsu shuppansha, 2006. pp 302.

Kamakura \& Hayama The Museum of Modern Art (ed.): Junzo Sakakura architect. Kamakura:Kenchiku Shiryo Kenkyusya, 2010.

Kokusai Kenchiku 12, №9. Septiembre 1936. Tokyo, 1936.

Le Corbusier; Jeanneret, Pierre: Le Corbusier et Pierre Jeanneret. Oeuvre Complète 1910-1929. Zurich: Publiée par Willy Boesiger, 1964.

Le Corbusier: Hacia una arquitectura. Barcelona: Ediciones Apóstrofe, S.L. 1998.

Mayekawa, Kunio: “Comentarios”. En Mokuyokai Zasshi, December 1937. Tokyo: Tokyo University. 1937. pp. 14. Recogido al inglés en Yuzuru, Tominaga: "Exploring the Ethical Spirit of Modern Architecture".". The Exhibition Organizing Committee for Kunio Maekawa Retrospective (ed): The Work of Kunio Maekawa: A Pioneer of Japanese Modern Architecture. Tokyo: Bijutsu shuppansha, 2006. pp 302.

Noboru, Kawazoe: Contemporary Japanese Architecture. Tokyo: Kokusai Bunka Shinkokai, 1968.

Quetglas, Josep: "Promenade Architecturale". En Web Architecture Magazine. No5 Ediciones Actar. Internet Editor: Yes.

Reynolds, Jonathan M.: Maekawa Kunio and the Emergence of Japanese Modernist Architecture. Berkeley: University of California Press, 2001. 
Sakakura Associates. Process: Architecture. N¹10. May 1993. Tokyo: Process Architecture CO. Ldt. 1993.

Sakakura, Junzo: “Japanese Pavilion for the International Exhibition, Paris 1937”. En Gendai Kenchiku, Junio 1939, No1. Tokyo, 1939. pp. 10-11.

Sakakura, Junzo: “Japanese Pavilion for the International Exhibition, Paris 1937”. En Gendai Kenchiku, Junio 1939, No1. Tokyo, 1939. Reeditado y traducido al inglés en Process: Architecture. "Sakakura Associates" May 1993, nº110. Tokyo: Process Architecture CO. Ldt. 1993. pp.32-34.

Sakakura, Junzo: “Kamakura Museum of Modern Art”. En Kenchiku Bunka, Junio 1963, No6. Tokyo, 1963. Reeditado y traducido al inglés en Process: Architecture. "Sakakura Associates" May 1993, n¹10. Tokyo: Process Architecture CO. Ldt. 1993. pp.46.

Tadayoshi, Fujiki: “Tokyo-Paris 1936-1937”. En Process: Architecture. "Sakakura Associates" May 1993, n¹10. Tokyo: Process Architecture CO. Ldt. 1993. pp.36-38.

The Exhibition Organizing Committee for Kunio Maekawa Retrospective (ed): The Work of Kunio Maekawa: A Pioneer of Japanese Modern Architecture. Tokyo: Bijutsu shuppansha, 2006.

Yuzuru, Tominaga: "Exploring the Ethical Spirit of Modern Architecture". The Exhibition Organizing Committee for Kunio Maekawa Retrospective (ed): The Work of Kunio Maekawa: A Pioneer of Japanese Modern Architecture. Tokyo: Bijutsu shuppansha, 2006. pp 305. 